DELAYED SERORESPONSE TO EBV INFECTION IN AN INFANT

954 WITH AIDS PRODROME. James $c$. Fackler, Patricia T. Mildvan, Richard F. Ambinder, William H. Adler James E. Nage1. Johns Hopkins School of Medicine, Dept. of Pediatrics, \& National Institute on Aging, Baltimore, MD

A 7 mo. old gir1, born to an IV drug dependent mother, presented with chronic diarrhea, impaired growth, hepatosplenomegaly \& generalized 1ymphadenopathy. Serum 1mmunoglobulins were elevated, but lymphocyte mitogen responses \& $\mathrm{T}$ cell subsets were normal. EBV genome was detected in the saliva \& in a spontaneous cell line grown from the patient's lymphocytes, however, anti-EBV antibody titers (VCA-IgM, VCA-IgG, EA \& EBNA) were $<1.10$. Following recovery from an episode of $\frac{\mathrm{s}}{\mathrm{s}}$. pneumoniae meningitis at age $10 \mathrm{mo}$. 1ymphocyte mitogen responses were decreased $\& T$ cell subsets abnormal $(T 4 / T 8=.3)$. Serum anti-EBV antibody remained undetectable until age 14 mo. (VCAIgG $1: 400)$. At $16 \mathrm{mo}$. this rose to $1: 2560$ and $\mathrm{EA}-\mathrm{R}$ was $1: 20$. Specific antibody to tetanus, diphtheria, pneumococcus and HTLV were present. Persistent tachypnea with a diffuse interstitial infiltrate developed at $11 \mathrm{mo}$. \& did not respond to treatment with trimethoprim-sulfa. Lung biopsy tissue showed a peribronchiolar 1ymphocytic infiltration consistant with EBV pneumonitis. Confirmation by DNA hybridization is pending. Pulmonary symptoms were unchanged by IV acyclovir. The patient's 1ymphocytes continue to readily form $\mathrm{EBV}^{+}$lymphoblast 1 ines. These data indicate that despite chronic, symptomatic, infection this child with an AIDS prodrome has developed a minimal antibody child with an AIDS prodrome has developed a minimal antibody
response to EBV. The relationship of EBV to the etiology of the AIDS prodrome is unknown.

\section{IMMUNOSUPPRESSION BY NEONATAL APOLIPOPROTEIN E}

955 Trudy M. Forte, Linda Curtiss, Paul Davis, and ratory, Univ. Calif., Berkeley, Dept. Immunology, Scripps Clinic, La Jolla and Children's Hosp. Med. Ctr., Oakland, CA.

Recent reports have suggested that in adults certain lipoproteins, particularly those carrying apolipoprotein (apo) E and apo $B$, play a role in suppression of the immune system. We have investigated the ability of lipoproteins from umbilical cord blood (CB) to suppress immune response. CB 11 poprote in concentrations are lower than those of adult, i.e., the low density lipoprote lipoprotein (HDL) level is $50 \%$ of adult. Apo E concentration in $C B$ is 2-fold higher than adult $(5.8 \pm 2.5 \mathrm{mg} / \mathrm{dl}$ vs. $3.1 \pm 0.9 \mathrm{mg} / \mathrm{dl})$. The ability of LDL and HDL to inhibit mitogen-stimulated ${ }^{3} \mathrm{H}$-thymidine uptake in adult peripheral biood mononuclear cells (PMC) was used as an in vitro test system to study immunosuppression. was used as an in vitro test system to study immunosuppression.
Relative to adult lipoproteins, CB LDL and HDL were 2 to 4 times more potent in inhibiting PMC proliferation. Radioimmunoassay showed a strong correlation between amount of apo E in CB LDL and HDL and PMC inhibition. Selective removal of apo E-containing lipoproteins decreased significantly the inhibitory effect in CB LDL and el iminated almost completely inhibition by HDL. Results indicate that $C B$ lipoproteins containing apo $E$ in association with apo $B$ and AI are capable of suppressing the immune response. with apo $B$ and $A I$ are capable of suppressing the immune response. high apo $E$ levels may have a functional significance in the establishment of self and maintenance of the fetus in utero.

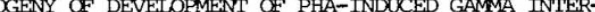

956 FERON (IFN) PRODUCTION BY LYMPHOCYTES OF NORNAL UCLA Sch. Med., Dept. Pediatrics, Ios Angeles,', Ca.

The increased severity of infections in young infants may be due to inmaturity of the neonatal inmune system. Studies have shown that lymphocytes from 1-7 day old infants make normal adult levels of alpha IFN, but have impaired production of PHA-induced ganma IFN. This impairment has been shown to be primarily due to a functionally inmature neonatal macrophage. Garma IFN production is inportant in recovery from viral infections and can also be used as a marker of macrophage function in infants. To determine the ontogeny of garma IFN production in vivo, we obtained blood from 40 healthy children (age 1 day to 12 yrs), and 13 adult controls. Whole blood (adjusted to $2 \times 10^{\circ}$ lymphs/mi) was incubated trols. Whole blood (adjusted to $2 \times 10^{5}$ lymphs/mi) was incubated
with PHA-A in RPMI for $48 \mathrm{hrs}$, and supernates assayed for IFN exwith PHA-A in RPMI for $48 \mathrm{hrs}$, and supernates assayed for IFN ex-
pressed in Intemational Units (IU) by protection of WISH human aminon cells from encephalomyocarditis virus challenge. All adults (13) produced IFN geometric mean titer (GMT) 114 IU (range 25-756 IU). In comparison healthy infants ages 0-75 days exhibited markedly decreased garma IFN with only $8 / 26$ producing any detectable IFN (range 0-480 IU), GMT 2.75 TU (p<.01). Infants from 75-180 days of age produced ganma IFN at intermediate levels of 0-240 IU GMT $=50(\mathrm{~N}=6)$. Adult levels of ganma IFN were produced by $7 / 8$ children $>180$ days old (180 days-12 yrs) levels $0-980 \mathrm{IU}$, (aMT=177 IU $(\mathrm{l}=8)$. This impaired gamma IFN production in infants $\leq 2 \frac{1}{2}$ mos. of $(I=8)$. This impaixed garma IFN production in infants $\leq 2 \frac{1}{2}$ mos.
age may represent a functionally inmature macrophage system and age may represent a functionally inmature macrophage system and
may help explain the increased morbidity and mortality from bacmay help explain the increased morbidity and mortality from bacyoung infants.
957 NEONAMAL AND PLACENTAL MACROPHAGES (Mळ) SURFACE ANTT957 GEN EXPRESSron. D.M. Glover, C.B. Wilson, (spon. by Dept. of Pediatrics, Seattle.

The fetus and newborn are afflicted by infections that suggest a relative impairment in immunity; $M \varnothing$ play an important role in the immune response by clearing and processing foreign material. We compared surface epitopes necessary for antigen (Ag) presentation on neonatal cord blood $M \varnothing$, fetal tissue $M \varnothing$ from the placenta, and adult blood Mø. Blood M $\varnothing$ were isolated by conventional methods. Placental $M \varnothing$ were obtained by enzyme digestion, density gradient separation, and selective adherence. Surface Ag expression was determined by indirect fluorescence microscopy using monoclonal antibodies towards: 1) Monomorphic HLA-DR determinants 7.2, L112 or 12.2 ; 2) a $M \varnothing$ surface epitope associated with enhanced accessory cell function-M $\varnothing 120$; and 3) a human M $\varnothing$ marker F13. Viability of blood $M \varnothing$ was $(\bar{x} \pm$ S.D.) $91 \pm 5.3$ and of placental $M \varnothing$ was $84 \pm 8$ (NS); non-specific esterase and $\bar{F} 13$ staining were $90 \pm 4$ and $87 \pm 4$ and were comparable for each $M \varnothing$ type. Comparable and persistent expression of HLA-DR and $M \varnothing 120$ were found for each $M \varnothing$ type. Adult Blood $M \varnothing$ Cord Blood $M \varnothing$ Placental $M \varnothing$ $\begin{array}{lcllllll}\text { Hrs. in cult. } & 0 & 24 & 96 & 0 & 24 & 96 & 0-24\end{array}$

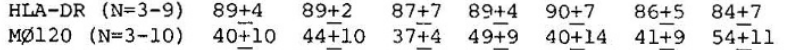
F.A.C.S. analysis of 0 and $96 \mathrm{hr}$, adult and cord $M \varnothing$ gave parallel but somewhat lower values. Thus, newborn $M \varnothing$ have the relevant. surface phenotypes for Ag presentation; further investigation is needed to define functional correlates.

\section{STUCTURAL BASIS FOR THE MULTIPLE FUNCTIONS OF \\ SECRETORY COMPONENT. RM Goldblum, CS Woodard, 058 JB Splawski, and RM Denney, University of Texas} Medical Branch, Galveston, Texas, Departments of Pediatrics and Human Biological Chemistry \& Genetics.

Secretory component (SC) plays a central role in the mucosal immune system. This polypeptide serves as the epithelial cell receptor and transporter for polymeric IgA (pIgA) and protects IgA from proteolysis. To evaluate the structural basis for these functions, we produced a large panel of monoclonal antibodies to human free SC (FSC) and SC bound to secretory IgA (bSC). We examined the reactivity of these antibodies with FSC, bSC and reduced and alkylated SIgA (R-A SIgA) by ELISA, and to membrane on a colon carcinoma cell line (HT29) by immunofluorescence.

Twenty one of 22 antibodies from fusions in which SIgA was the immunogen bound preferentially to bSC, while 19 of 25 antibodies from FSC fusions were specific to FSC. These specifici-
ties were confirmed by reactions with complexes formed in vitro ties were confirmed by reactions with complexes formed in vitro
from pIgA and FSC. Few antibodies reacted with both FSC and bSC. Further testing with R-A SIgA allowed definition of at least 5 groups of epitopes on SC. Only a portion of antibodies reactive with one of these epitope groups mediated intense membrane and cytoplasmic immunofluorescent staining of HT29 cells.

These results are consistent with the synthesis of SC as an intergal membrane protein. The frequency of unique epitopes on the various physical forms of human SC indicates that this peptide undergos marked changes in tertiary structure or becomes integrated into surrounding structures. These modifications may be related to the various functions of SC.

SUCCESSFUL BONE MARROW TRANSPLANTATION IN DIGEORGE

959 sYNDROME. Alan B. Goldsobel, Guillermo R. Mendoza, DiGeorge $\frac{E \text {. Richard Stiehm, UCLA, Dept. of Pediatrics, L.A., }}{\text { syndrome is a congenital immunodeficiency disorder }}$ with variable degrees of $\mathrm{T}$ cell immunity. Immunologic reconstitution with fetal thymlc tissue or hormones has shown varied success, and appropriate tissue is difficult to obtain.

A patient with DiGeorge syndrome presented at day 3 with hypocalcemia, seizures, Tetralogy of Fallot, and typical facies. Thymus shadow was absent on X-ray. Parathormone level was low. Evaluation at 26 weeks showed normal lymphocyte count, $T$ cells $16 \%$ by $\mathrm{E}$ rosette, $1 \%$ by pan- $\mathrm{T}$ cell monoclonal antibody, B cells $65 \%$, IgG $277 \mathrm{mg} / \mathrm{dl}$, IgM $61 \mathrm{mg} / \mathrm{dl}$, IgA $0, \operatorname{IgE} 15 \mathrm{IU} / \mathrm{ml}$, isohemagglutinins present at titer $1: 1$. Phytohemagglutinin (PHA), antigen and allogeneic stimulation were flat. Factor thymic serique was present at $1 / 4$ (low), thymosin $\alpha_{1}$ was $700 \mathrm{pg} / \mathrm{ml}$ (normal).

Because of the profound $\mathrm{T}$ cell defect with antibody defect, we performed bone marrow transplant (BMT) with $1.16 \times 10^{9}$ nucleated cells $/ \mathrm{kg}$ from her HLA,A,B,C matched, DR mismatched, MLC nonreactive brother without conditioning. There was no evidence of GVH disease. PHA stimulated lymphocytes now show XY karyotype and $T$ cells are $43 \%$ by $E$ rosette. EB virus stimulated $B$ cells are 29/30 XY, but DR type is unchanged. Immunoglobulins are normal, antibody and in vitro proliferative response to injected antigen are present.

This experience indicates that little thymic function is necessary for successful BMT, but does not determine whether there has been central or peripheral reconstitution. 